\title{
Investigation of distributed generation units placement and sizing based on voltage stability condition indicator (VSCI)
}

\author{
Arvind Raj ${ }^{1}$, Nur Fadilah Ab Aziz ${ }^{2}$, Zuhaila Mat Yasin ${ }^{3}$, Nur Ashida Salim ${ }^{4}$ \\ ${ }^{1,2}$ Department of Electrical Power Engineering, Universiti Tenaga Nasional, Malaysia \\ ${ }^{3,4}$ Faculty of Electrical Engineering, Universiti Teknologi MARA, Malaysia
}

\begin{tabular}{l}
\hline Article Info \\
\hline Article history: \\
Received Aug 8, 2018 \\
Revised Feb 2, 2019 \\
Accepted Mar 6, 2019 \\
\hline
\end{tabular}

\section{Keywords:}

Distributed generation

Maximum loadability

Power losses

Voltage stability

Voltage stability index

\begin{abstract}
Voltage instability in power distribution systems can result in voltage collapse throughout the grid. Today, with the advanced of power generation technology from renewable sources, concerns of utility companies are much being focused on the stability of the grid when there is an integration of distributed generation (DG) in the system. This paper presents a study on DG units' placement and sizing in a radial distribution network by using a predeveloped index called Voltage Stability Condition Index (VSCI). In this paper, VSCI is used to determine DG placement candidates, while the value of power losses is used to identify the best DG placement. The proposed method is tested on a standard 33-bus radial distribution network and compared with existing Ettehadi and Aman methods. The effectiveness of the method is presented in terms of reduction in power system losses, maximization of system loadability and voltage quality improvement. Results show that VSCI can be utilized as the voltage stability indicator for DG placement in radial distribution power system. The integration of DG is found to improve voltage stability by increasing the system loadability and reducing the power losses of the network.
\end{abstract}

Copyright (C) 2019 Institute of Advanced Engineering and Science. All rights reserved.

\section{Corresponding Author:}

Nur Fadilah Ab Aziz, Department of Electrical Power Engineering, College of Engineering, Universiti Tenaga Nasional (Uniten), Jalan Ikram-Uniten, 43000 Kajang, Selangor, Malaysia.

Email: nfadilah@uniten.edu.my

\section{INTRODUCTION}

Distributed generation attributes to generation of power at the point of consumption or the location of load $[1,2]$. Distributed generation also refers to small scale generation that is not directly connected to the bulk distribution system and non-centrally dispatched [3]. In published works, there are a number of different terms and definitions are used for the description of distributed generation [4]. The term 'embedded generation' is often used in Anglo-American countries, 'dispersed generation' is used by North American countries and the term 'decentralised generation' is applied in Europe and parts of Asia [4, 5]. The name 'distributed generation (DG)' is recommended to be used all over the world based on the literature survey [4, 5]. Power generation at the location of load decreases the losses due to transmission over long distances as well as other costs associated with the distribution systems. The complexity and the inefficiencies from the systems are also minimized with the emergence of DG [6]. In many cases, DG can supply electricity at a lower cost with improved power reliability and security and resulted to fewer environmental issues compared to conventional generators [7].

Voltage stability is defined as the ability of a power system to maintain acceptable voltage levels at all buses within the system [8]. The definition includes the voltage of buses under normal condition and after disturbance in the network. A state of voltage instability is experienced in a system when there is a continuous or uncontrollable drop in the magnitude of voltage either after a disturbance, load increase or after 
a change occurs in operating conditions. Voltage instability can result in voltage collapse throughout the grid, in which case the voltage falls to an unacceptable, low value. Voltage collapse is a common occurrence in power systems which are heavily loaded, faulted or having shortage in reactive power $[9,10]$. The change in voltage is directly proportional to change in load [11].

The relation of grid voltage stability and grid connected DG can be analysed in a multitude of methods. As much as the reactive power support sourced from capacitor banks can be utilised to reduce power loss, incorrect placement of the capacitors can further increase the line losses [12]. Capacitors are also unable to support the network with real power when the situation arises. DG systems offer a better option as it can be utilised to support the grid with both real and reactive power, as long as the placement and the sizing can be optimally determined. Inappropriate sizing and location of distributed generation units may also increase the system losses as well as the operating costs. Therefore, it is necessary to investigate the impacts of DG placement and sizing to the system.

Nannapaneni et al. provide a comprehensive study to evaluate the effectiveness of various PQ and QV voltage stability indices on utilizing distributed generation (DG) units optimally within certain limits and constraints [13]. The indices are used to identify the weakest buses and calculate the stability margin of a system. The study concludes that QV sensitivity indices need to be considered along with PV sensitivity indices for the allocation of DGs. The study also shows how the selection of the appropriate voltage stability index varies depending on the DG bus model in the simulation, either as a PV or PQ model. The study proposes a more direct method in suggesting QV index in analysing voltage stability as QV curve method does not require the system to be represented as a two-bus system. However, Q-V curve could only be used for a system with a constant power level, thus it needs P-V curve method to be performed as well.

In a research by Nahilia and Boudour, a static power flow study based on the analysis of Djanet power system behaviour in terms of DG contribution and voltage profile evolution in Algeria [14]. A new voltage stability index is used to identify the weakest node in the system. This paper states that the optimal DG power factor must be closer to the power factor of the combined load contribution in order to minimize power losses. The results of this research show that the integration of DG improves the voltage profile and decreases the total power loss in the system significantly. The research, however, does not consider the sizing and the location of DG in the study.

Wang et al. investigate the impact of wind power on static voltage stability [15]. The probabilistic static voltage stability of power systems is analysed based on Probabilistic Load Flow (PLF), which is able to take uncertain factors into consideration, for example load distribution and randomness of input variables. Quasi-Monte Carlo (QMC) simulation using Sobol sequence is applied to solve PLF after considering the random input variables, while Nataf transform is used to manage the correlation of wind power. The results presented in this paper are compared with the data generated from Monte-Carlo Simulation (MCS) combined with Simple Random Sampling method to show the improvement made. However, the Nataf transform and a Sobol sequence which are needed for this method makes the process to be quite tedious.

Aman et al. Has introduced a new index for the placement and sizing of DG units [16]. The allocation and sizing of DG units in this research using the proposed index is to determine the bus with the most voltage sensitivity and minimum total power losses. The index, power stability index (PSI), is developed by taking stable node voltage in consideration. The simulation results show that the DG units improve the voltage profile of the network and increase the system voltage stability. The overall system capacity also increases while reducing the line losses. The proposed algorithm is found to consume less computation time compared to the Golden Section Search (GSS) algorithm by 50-60\%. However, the performance of the technique depend heavily on the initial guess and the algorithm is developed with several theoretical assumptions such as continuity, convexity and differentiability which may not be suitable for optimization problems.

Based on the literature reviews, it can be concluded that there are many different indices used for voltage stability analysis as well as many different approaches for DG placement and sizing. Some of the voltage stability indices are not entirely reliable on their own and need to be calculated together with another index for it to be accurate. While most indices are comparatively reliable, some of the approaches pursued for the placement and sizing of DG are too resource extensive. A simpler and less resource extensive method is needed for the voltage stability analysis in the presence of DG units. This paper presents the ability of Voltage Stability Condition Indicator (VSCI) in DG placement. Previously, the capability of VSCI as the voltage stability indicator in transmission system has been proven in [17-20]. In this paper, VSCI is evaluated in a radial distribution system network. The objective of DG integration in this paper is to improve the system loadability and reduce power system losses.

Int J Pow Elec \& Dri Syst, Vol. 10, No. 3, Sep 2019 : 1317 - 1323 


\section{RESEARCH METHOD}

\subsection{Voltage stability condition indicator (VSCI)}

VSCI has been proposed in [17] and is derived from the current equation in a complex form of a simple 2-bus Thevenin equivalent system. For a typical transmission line, VSCI can be calculated by

$$
V S C I=\frac{4 Z_{T h}^{2}\left(P^{2}+Q^{2}\right)}{\left.\left(2 Z_{T h} \cos \beta+Q \sin \beta\right)-E_{T h}{ }^{2}\right)^{2}} \leq 1
$$

Where,

$P$ and $Q=$ active and reactive power load,

$E_{T h} \angle \delta=$ Thevenin voltage,

$Z_{T h} \angle \beta=$ Thevenin impedance or the total equivalent impedance across the bus, and $\delta$ and $\beta$ are their corresponding phase angles.

In order to maintain the stability of the system, VSCI value must be less than or equal to one as in equation (1). Any bus that has VSCI value near to one implies that the bus is approaching its collapse point. Previously, VSCI has been tested to be able to evaluate the voltage stability in transmission line [17-20]. This paper aims to test the capability of VSCI to evaluate the voltage stability in radial distribution system.

\subsection{DG placement and sizing based on VSI}

Today, DGs are used to improve the traditional electric power systems [21-22]. These technologies include small or micro gas turbines, fuel cells, wind and solar energy, biomass, small hydro-power and others. In order to achieve the benefits of integrating DG units into the power system, an appropriate place and size of the DG units installed must be selected. Installing the units at inappropriate places may weaken the stability and reliability of the power system [23]. In this paper, the study is being divided into two phase. In the first phase, the candidate locations of DG units is chosen according to VSCI value. This phase is very useful to minimize the size to be used in the optimization process for the second phase especially for very large size of power system network. Secondly, the best location and sizing of the DG units are then determined based on the objective function which are in this paper the aim is to minimize the power losses and maximize the system loadability. Figure 1 (a) shows the flowchart for the first phase of the study.

In the second phase of the study as shown in Figure 1 (b), the ranking of the weakest buses based on the VSCI values are used to determine the best placement of DG units to be installed into the system. The top 10 weak buses with VSCI above 0.95 are used to place a DG unit at each location and the effects on the network power losses are studied. The bus that give the minimum value of power losses are chosen to be the optimal location. Next, to calculate the size of DG unit to be installed, several parameters are taken into account which are the DG penetration percentage $(\mathrm{Pn})$, power factor $(\mathrm{pf})$ value of the system and number of DG units (Num). In this paper, the size of DG are determined by varying the penetration percentage and power factor. As a result, in this paper, the best penetration level of DG and power factor value of the system can be identified. The types of DG used are made constant which can inject both, active and reactive power. The value of apparent power, $S$, real power, $P$ and reactive power, $Q$ to be supplied by the DG unit is calculated using the steps below:

a. The penetration level, $P n$ and the total apparent load, $S_{\text {load }}$ in the network is used to calculate the apparent power to be supplied by the DG unit, $S_{D G}$ as shown in the formula below:

$$
\begin{aligned}
P n & =\frac{S_{D G}}{S_{\text {load }}} \times 100 \% \\
S_{D G} & =\frac{P n \times S_{\text {load }}}{100 \%}
\end{aligned}
$$

b. The real power to be supplied by the DG unit, $P_{D G}$ is calculated by using the value of DG apparent power and the power factor set for the DG unit:

$$
P_{D G}=p f \times S_{D G}
$$

c. The reactive power to be supplied by the DG unit, $Q_{D G}$ is calculated using the formula below:

$$
Q_{D G}=\sqrt{S_{D G}^{2}-P_{D G}^{2}}
$$


d. The real and reactive power to be supplied by the DG unit(s) is divided equally among the number of units to be integrated in the network:

$$
\begin{aligned}
& P=\frac{P_{D G}}{N u m} \\
& Q=\frac{Q_{D G}}{N u m}
\end{aligned}
$$

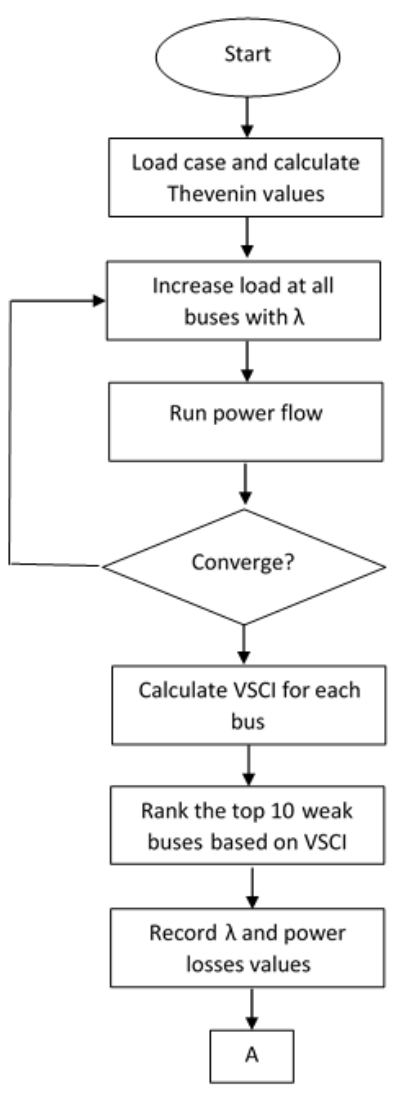

(a)

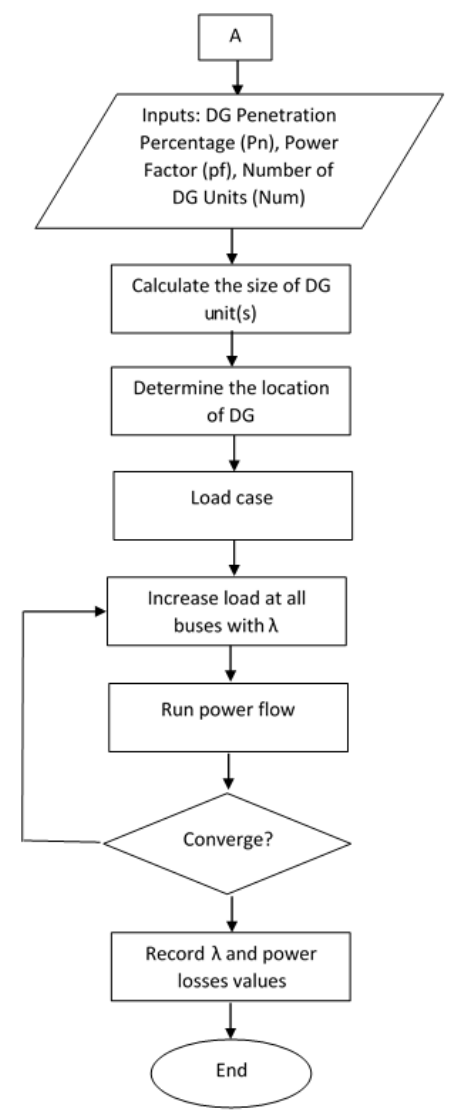

(b)

Figure 1. Flowchart of the developed algorithm for; (a) DG placement, (b) DG sizing.

\section{RESULTS AND DISCUSSION}

The simulation in this paper was computed using the 33-bus radial distribution network [24]. This is a radial distribution system with 33 buses, 5 tie lines or looping branches. It consists of 1 generator bus as a swing bus, 32 load buses and 37 interconnecting branches. Table 1 shows the system details of 33-bus radial distribution network.

Table 1. 33-bus radial distribution system's details

\begin{tabular}{cccc}
\hline $\begin{array}{c}\text { Total Active Load in } \mathrm{kW} \\
(\mathrm{P})\end{array}$ & $\begin{array}{c}\text { Total Reactive Load in } \\
\text { kVAR }(\mathrm{Q})\end{array}$ & $\begin{array}{c}\text { Total Apparent Load in } \\
\text { kVA }(\mathrm{S})\end{array}$ & $\begin{array}{c}\text { System Power } \\
\text { Factor }(\mathrm{pf})\end{array}$ \\
\hline 3715 & 2300 & 4369.35 & 0.8502 \\
\hline
\end{tabular}

\subsection{Weak buses based on VSCI}

In the first phase of research, in order to determine weak busses, load for every bussed were increased until the system reached its maximum loadability limit. VSCI value was then calculated and the 
system was ranked according to VSCI value. The VSCI values that close to unity were considered as weak buses. Table 2 shows the rank of top 10 weak busses at the maximum loadability of the system. The results are consistent with [25] and the voltage buses magnitudes which give almost the same weak buses ranking.

Table 2. Top 10 busses with highest VSCI for maximum loadability

\begin{tabular}{ccc}
\hline Bus No & Voltage (p.u.) & VSCI \\
\hline 18 & 0.429 & 0.9999 \\
17 & 0.4337 & 0.9849 \\
16 & 0.4494 & 0.9527 \\
32 & 0.4609 & 0.9443 \\
33 & 0.4589 & 0.9331 \\
31 & 0.4676 & 0.9265 \\
15 & 0.4598 & 0.9126 \\
14 & 0.4705 & 0.8828 \\
30 & 0.4975 & 0.8750 \\
13 & 0.4878 & 0.8646 \\
Real Power Losses (MW) & 7.8640 \\
Reactive Power Losses (MVAR) & 5.3385 \\
\hline
\end{tabular}

\subsection{DG placement and sizing}

A DG unit supplying both real and reactive power was placed at each weak buses ranked as the top ten based on VSCI. In this paper, the type of DG units placed in the network can inject both active and reactive power. The performance of DG units with different operating power factors are evaluated based on the resulting maximum loadability of the network, which are shown in Table 3 . The calculation to determine amount of DG reactive and active power injected is as discussed in Section 2.2. In the beginning, the size was set to $40 \%$ penetration level $(P n)$ and at operating power factor of 0.85 [25-26]. The network loadability was set constant at 3.5, which was the maximum loadability of the base case network. The real and reactive power losses of the simulation conducted were analysed. From Figure 3, the system has the lowest power losses when a DG unit was placed at buses 32, 33 and 31, respectively. Therefore, in this paper, buses 32,33 and 31 are determined as the best location for the DG placement. This result is consistent with the findings obtained in [25-26].

The size of DG was determined by varying the penetration level $(P n)$ of DG. In this paper, the penetration level of DG was varied ranging from $20 \%$ to $80 \%$, from one unit of DG up to three units of DG evaluated in the system. Based on Table 3, it can be seen that the network has the highest maximum loadability when the DG unit(s) were operating at 0.85 power factor. This is due to the DG operating power factor is being closer to the system power factor, which is about 0.85 as tabulated in Table 1 . This result is consistent with the findings reported in [26] which states that the maximum loadability of the system when being integrated with DG can be achieved when the DG operating power factor is similar to the system power factor. Table 3 also shows that although the size and the number of DG units are increased, the maximum loadability achieved are more less the same for placement of two DG units. Hence, considering the installation and maintenance cost, two DG units with $40 \%$ penetration level are recommended for 33-bus radial distribution network. This result is again consistent with the finding obtained in [26] which confirms the capability of VSCI and the value of power losses obtained in DG placement and sizing.

Table 3. Comparison of maximum loadability of different DG penetration level and power factor.

\begin{tabular}{cccccccccccccc}
\hline & \multicolumn{4}{c}{ DGs = 1 } & \multicolumn{4}{c}{ DGs = } & \multicolumn{4}{c}{ DGs = 3 } \\
pf & \multicolumn{3}{c}{ DG Penetration (\%) } & \multicolumn{3}{c}{ DG Penetration (\%) } & \multicolumn{4}{c}{ DGentration (\%) } \\
& 20 & 40 & 60 & 80 & 20 & 40 & 60 & 80 & 20 & 40 & 60 & 80 \\
\hline 1 & 3.89 & 4.06 & 4.19 & 4.3 & 3.95 & 4.25 & 4.52 & 4.76 & 3.94 & 4.24 & 4.52 & 4.77 \\
0.95 & 3.92 & 4.12 & 4.28 & 4.42 & 4.01 & 4.38 & 4.72 & 5.04 & 4 & 4.37 & 4.73 & 5.07 \\
0.9 & 3.93 & 4.13 & 4.3 & 4.44 & 4.02 & 4.4 & 4.77 & 5.11 & 4.02 & 4.4 & 4.77 & 5.13 \\
0.85 & 3.93 & 4.14 & 4.3 & 4.44 & 4.03 & 4.42 & 4.78 & 5.14 & 4.02 & 4.41 & 4.79 & 5.16 \\
0.8 & 3.93 & 4.13 & 4.3 & 4.44 & 4.03 & 4.42 & 4.78 & 5.14 & 4.02 & 4.41 & 4.79 & 5.16 \\
0.75 & 3.92 & 4.13 & 4.29 & 4.43 & 4.02 & 4.41 & 4.78 & 5.13 & 4.02 & 4.41 & 4.79 & 5.15 \\
\hline
\end{tabular}




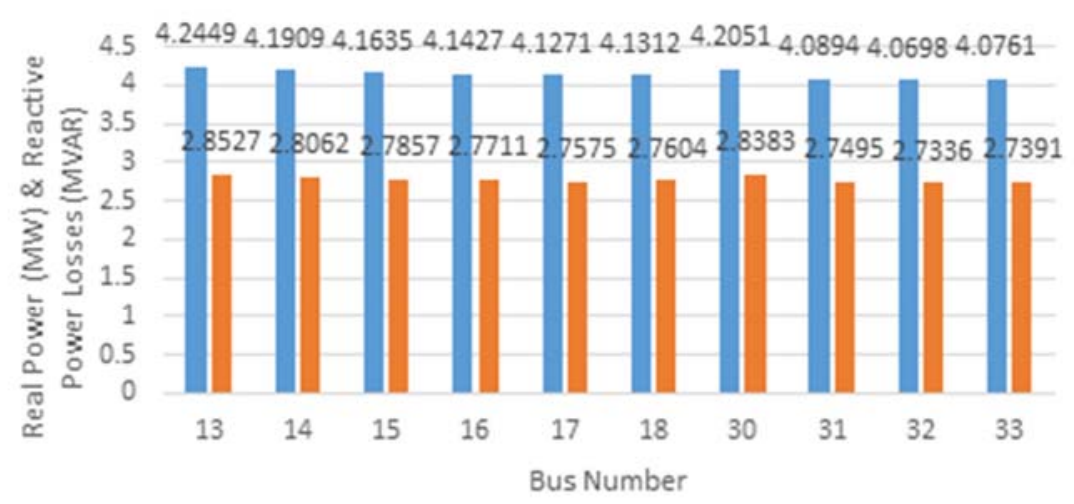

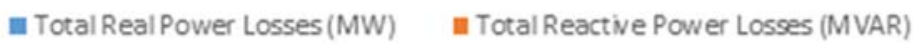

Figure 3. Comparison of power losses for a unit DG placed at weak buses.

\section{CONCLUSION}

In this paper, an evaluation of a voltage stability index for DG placement in radial distribution network is presented. VSCI is used to determine DG placement candidates, while power losses is used to choose the best DG places. The weak buses ranking based on VSCI gives almost similar result when compare to voltage buses magnitudes and also findings in [25]. Therefore, it can be concluded that VSCI can be utilized as the stability indicator of radial distribution power system. The study is conducted on the 33-bus radial distribution network, and the results show the impacts of DG, both in total power loss reduction and maximum loadability improvement under stressed operation. Results show that, with 40\% DG penetration only, power losses can be reduced up to $48 \%$ and maximum loadability of the system can increase up to $30 \%$. From above results, it can also be observed that the performance of different number of DG units' placement can give approximately the same results. This result is again consistent with the findings obtained in [26]. Therefore, based on results presented in this paper, VSCI is proven to be able to determine the weakest bus in radial distribution system for DG placement and sizing.

\section{ACKNOWLEDGEMENTS}

The authors would like to thank Ministry of Higher Education (MOHE) of Malaysia through a research grant of 20180112FRGS for the financial support to this research.

\section{REFERENCES}

[1] L. J. Dulau and M. Abrudean, "Hybrid Wind and Solar Power System," Journal of Computer Science \& Control Systems, vol. 6(1), pp. 30-33, May 2013.

[2] L. I. Dulau, M. Abrudean and D. Bica, "Effects of Distributed Generation on Electric Power Systems," In Procedia Technology, vol. 12, pp. 681-686, 2014.

[3] H. A. Attia, Z. H. Osman, M. El-Shibini, and A. A. Moftah, "An Assessment of Distributed Generation Impacts on Distribution Networks using Global Performance Index," Nature and Science, vol. 8(9), pp. 150-158, 2010.

[4] T. Ackerman, G. Andersson and L. Soder, "Distributed Generation: A definition," Electric Power System Research, vol. 57(3), pp. 195-204, 2001.

[5] W. El-Khattam and M. M. A. Salama, "Distributed Generation Technologies, Definitions and Benefits," Electric Power System Research, vol. 71(2), pp. 119-128, 2004.

[6] R Sharma, M. Singh and D. K. Jain, "Power System Stability Analysis with Large Penetration of Distributed Generation," 6th IEEE Power India International Conference (PIICON), Delhi, 2014.

[7] D. Khani, A. S. Yazdankhah and H. M. Kojabadi, "Impacts of Distributed Generations on Power System Transient and Voltage Stability," International Journal of Electrical Power \& Energy Systems, vol. 43(1), pp. 488-500, 2012.

[8] I. Kumaraswamy, S. Tarakalyani and B. V. Prasanth, "Comparison of Voltage Stability Indices and its Enhancement Using Distributed Generation," Proceedings of the World Congress on Engineering, London, 2016.

[9] N. T. Linh and T. T. Chuong, "Voltage stability analysis of grids connected wind generators," Proceedings of 4th IEEE Conference Industrial Electronics and Applications (ICIEA 2009), pp. 2657-2660, 2009.

[10] A. Kazemi and M. Sadeghi, "Distributed Generation Allocation for Loss Reduction and Voltage Improvement," in Asia-Pacific Power and Energy Engineering Conference, Wuhan, 2009.

Int J Pow Elec \& Dri Syst, Vol. 10, No. 3, Sep 2019 : 1317 - 1323 
[11] E. Youssef, R. M. El Azab and A. M. Amin, "Comparative study of voltage stability analysis for renewable energy grid-connected systems using PSS/E," Southeast Conference, Fort Lauderdale, 2015.

[12] P. Mehta, P. Bhatt and V. Pandya, "Optimal selection of distributed generating units and its placement for voltage stability enhancement and energy loss minimization," Ain Shams Engineering Journal, 2015.

[13] G. Nannapaneni, T. M. Masaud and R. Challoo, "A comprehensive analysis of voltage stability indices in the presence of distributed generation," IEEE Conference on Technologies for Sustainability (SusTech), Ogden, 2015.

[14] H. Nahilia and M. Boudour, "Voltage stability analysis and optimal distributed generators placement study on Algerian power network," 3rd International Conference on Control, Engineering \& Information Technology (CEIT), Tlemcen, 2015.

[15] H. Wang, X. Xu, Z. Yan, Z. Yang, N. Feng and Y. Cui, "Probabilistic static voltage stability analysis considering the correlation of wind power," International Conference on Probabilistic Methods Applied to Power Systems (PMAPS), Beijing, 2016.

[16] M. M. Aman, G. B. Jasmon, H. Mokhlis and A. H. A. Bakar, "Optimal placement and sizing of a DG based on a new power stability index and line losses," International Journal of Electrical Power \& Energy Systems, vol. 43(1), pp. 1296-1304, 2012.

[17] N. F. Ab Aziz, T. K. A. Rahman, Z. Zakaria, "Voltage stability prediction by using Artificial Immune Least Square Support Vector Machines (AILSVM)" IEEE 8th International Power Engineering and Optimization Conference, PEOCO, no. 6814501, pp. 613-618, 2014.

[18] N. F. Ab Aziz, T. K. A. Rahman, Z. Zakaria, "Reactive power planning for maximum load margin improvement using Fast Artificial Immune Support Vector Machine (FAISVM)," International Review of Automatic Control, vol. 5(7), pp. 436-447, 2014.

[19] N. F. Ab Aziz, T. K. A. Rahman, Z. Zakaria, "A new technique for maximum load margin estimation and prediction," ARPN Journal of Engineering and Applied Sciences, vol. 23(10), pp. 17566-17572, 2015.

[20] N. F. A. Aziz, N.F.A., N. A. Rahmat, N.A., F. Muhammad-Sukki, T. K. A. Rahman, Z. M. Yasin, N. A. Wahab, N.A. Salim, "A new weak area identification method in power system based on voltage stability," Journal of Telecommunication, Electronic and Computer Engineering, vol. 2-11(9), pp. 171-177, 2017.

[21] J. B. V. Subrahmanyam, P. Alluvada, Bandana, K. Bhanupriya and C. Shashidhar, "Renewable Energy Systems: Development and Perspectives of a Hybrid Solar-Wind System," Engineering, Technology \& Applied Science Research, vol. 2(1), 2012

[22] A. S. O. Ogunjuyigbe, T. R. Ayodele and O. O. Akinola, "Impact of distributed generators on the power loss and voltage profile of sub-transmission network," Journal of Electrical Systems and Information Technology, vol. 3(1), pp. 94-107, 2016.

[23] U. Sultana, A.B. Khairuddin, M.M. Aman, A.S. Mokhtar, N. Zareen, "A review of optimum DG placement based on minimization of power losses and voltage stability enhancement of distribution system," Renewable and Sustainable Energy Reviews, no. 63, pp. 363-378, 2016.

[24] A. Wazir and N. Arbab, "Analysis and optimization of IEEE 33 bus radial distributed system using optimization algorithm," Journal of Emerging Trends in Applied Engineering, vol. 1(2), pp. 17-21, 2016.

[25] M. Ettehadi, H. Ghasemi, S. Vaez-Zadeh, "Voltage stability-based DG placement in distribution networks," IEEE Transactions on Power Delivery, vol. 1(2)8, pp. 171-178, 2013.

[26] M. M. Aman, G. B. Jasmon, A. H. A. Bakar and H. Mokhlis, "A new approach for optimum simultaneous multiDG distributed generation Units placement and sizing based on maximization of system loadability using HPSO (hybrid particle swarm optimization) algorithm," Energy, vol. 66, pp. 202-215, 2014. 